\title{
Efficient and Stable Low Iridium Loaded Anodes for PEM Water Electrolysis Made Possible by Nanofiber Interlayers
}

\author{
Friedemann Hegge, Florian Lombeck, Edgar Cruz Ortiz, Luca Bohn, Miriam von Holst, \\ Matthias Kroschel, Jessica Hübner, Matthias Breitwieser, Peter Strasser,* and Severin Vierrath*
}

Cite This: ACS Appl. Energy Mater. 2020, 3, 8276-8284

Read Online

\section{ACCESS | \\ Џll Metrics \& More \\ Article Recommendations \\ Supporting Information}
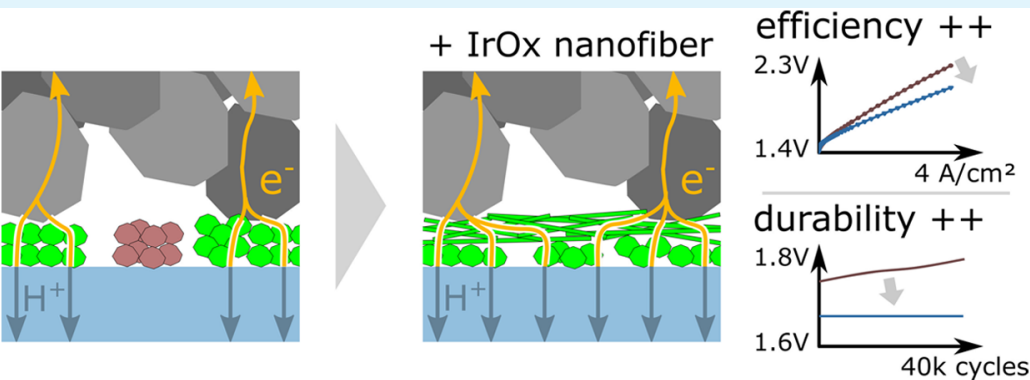

ABSTRACT: Significant reduction of the precious metal catalyst loading is one of the key challenges for the commercialization of proton-exchange membrane water electrolyzers. In this work we combine IrOx nanofibers with a conventional nanoparticle-based IrOx anode catalyst layer. With this hybrid design we can reduce the iridium loading by more than $80 \%$ while maintaining performance. In spite of an ultralow overall catalyst loading of $0.2 \mathrm{mg}_{\mathrm{Ir}} / \mathrm{cm}^{2}$, a cell with a hybrid layer shows similar performance compared to a state-of-the-art cell with a catalyst loading of $1.2 \mathrm{mg} / \mathrm{r} / \mathrm{cm}^{2}$ and clearly outperforms identically loaded reference cells with pure IrOx nanoparticle and pure nanofiber anodes. The improved performance is attributed to a combination of good electric contact and high porosity of the IrOx nanofibers with high surface area of the IrOx nanoparticles. Besides the improved performance, the hybrid layer also shows better stability in a potential cycling and a $150 \mathrm{~h}$ constant current test compared to an identically loaded nanoparticle reference.

KEYWORDS: PEM water electrolyzers, ultralow loading, durability, catalyst morphology, nanofibers

\section{INTRODUCTION}

Polymer electrolyte membrane (PEM) water electrolysis is a key technology for a sustainable hydrogen economy, but costs still have to be reduced to be competitive with hydrogen production from fossil resources. ${ }^{1-3}$ Currently, bipolar plates and porous transport layers make up for more than half of the PEM water electrolyzer stack costs. ${ }^{4,5}$ However, with decreasing costs for these components the noble metal based catalysts necessary for high conversion rates and efficiencies become a major cost driver. ${ }^{5}$ The platinum required for the hydrogen evolution reaction (HER) can generally be reduced to values below $0.1 \mathrm{mg} / \mathrm{cm}^{2}$ without significantly losing performance. ${ }^{6}$ In contrast, reducing the amount of iridium for the oxygen evolution reaction (OER) remains a key challenge for PEM water electrolysis. ${ }^{2}$ In state-of-the-art electrolysis around $0.5 \mathrm{~kg}$ of iridium is required per megawatt installed electrolyzer power. ${ }^{7}$ Considering the current iridium production of only $5 \mathrm{t}$ per year, it becomes evident that with state-ofthe-art loadings the installed PEM water electrolysis capacity will not break any time soon into the required terawatt scale. ${ }^{2}$ For this reason, reducing the iridium loading at the anode from the current state-of-the-art $\left(1-3 \mathrm{mg} / \mathrm{cm}^{2}\right)$ to values below 0.5 $\mathrm{mg} / \mathrm{cm}^{2}$ is a primary focus of current research and development. ${ }^{5}$ However, when reducing the loading, two major challenges arise: low durability and low conversion efficiency. ${ }^{8}$ The lack of durability can be explained by the intrinsic mechanical instability of the very thin anode layers (in the lower micrometer range), which in the current state-of-the-art consist of iridium-based nanoparticles and a binding ionomer applied onto the ionomer membrane. Also, iridium per se slowly dissolves during operation, leading to a lower catalytically active surface area and electrically isolated catalyst material. ${ }^{9,10}$ The uneven current distribution creates local activity hot spots, which may lead to accelerated degradation of the membrane electrode assembly (MEA). ${ }^{11}$ The same mechanism is the cause for poor efficiencies of low iridium

Received: April 2, 2020

Accepted: August 10, 2020

Published: August 10, 2020 
loaded anodes. Recent studies show that low loadings and therefore thin electrodes lead to poor electrical contact to the outer porous transport layer (PTL), which provides for electron, water, and oxygen transport to and from the anode. As a consequence, isolated parts of the anode catalyst layer (CL) do not contribute to the OER, which is the main cause for the high overpotential and poor efficiency. ${ }^{12,13}$

The challenges outlined above suggest that the solution to a significant reduction of Ir loading without loss of performance and durability lies, first, in a better catalyst utilization by improving electric contact and accessibility to the catalyst material and, second, in increasing the in-plane conductivity of the catalyst layer. In fact, three approaches have been shown to partly mitigate the losses of performance and durability of low loaded anodes. It is worth noting that besides the effect of each individual approach a combination of various approaches is viable and presumably enables further performance improvements. The first approach is applying a microporous interlayer (MPL) between PTL and CL. Lettenmeier et al. first proposed a $\mathrm{Ti}$ interlayer that was fabricated via vacuum plasma spraying. ${ }^{14}$ In their work, it is shown that the interlayer reduces mass transport losses of the PTL. However, as reported in a recent study, bulk mass transport of current stateof-the-art PTLs plays only a minor role with respect to the overall mass transport losses. ${ }^{13}$ Schuler et al. showed that a major part of the improved performance of the MPL approach stems from an increased catalyst utilization due to a better contact of the transport layer to the catalyst. Besides kinetic and ohmic benefits, the higher catalyst utilization is assumed to reduce the local mass transport resistance at or near the catalyst surface. The second approach is increasing the conductivity and accessibility in the catalyst layer itself by applying a support material resulting in a thicker catalyst layer. In this regard, introducing a conductive support material like titanium has successfully demonstrated increased performance and durability. ${ }^{15}$ The third approach is modifying the CL microstructure. Performance enhancements could be achieved by using core-shell catalysts and other microstructure modifications, which enabled higher electron conductivity and catalyst accessability. ${ }^{16-18}$ The most successful approaches are based on increasing the aspect ratio, which is the ratio between the shortest and the longest dimension of the catalyst particles. In 2015, Lewinski et al. presented whisker-shaped iridium oxide ( $\mathrm{IrOx}$ ) nanofibers (nanostructured thin films) as an OER catalyst, clearly outperforming $\mathrm{IrOx}$ nanoparticle catalysts in PEMWE cells. ${ }^{19}$ Recently, several groups presented iridium-based nanofibers for the OER,,$^{20-22}$ with the work of Alia et al. demonstrating very high activities in operating electrolyzer cells. ${ }^{21}$ However, using only high aspect ratio nanofibers as a catalyst layer increases accessibility and electrical conductivity but comes with the downside of a reduced electrochemically active surface area (ECSA) in comparison to high surface nanoparticles.

In this work, we use the advance in electrospun $\mathrm{IrOx}$ nanofibers to apply an interlayer with high in-plane conductivity on a conventional high surface $\mathrm{IrOx}$ nanoparticle catalyst layer. With this novel hybrid design we can significantly reduce the iridium loading while maintaining performance and durability.

\section{EXPERIMENTAL SECTION}

Nanofiber Synthesis. Electrospinning was performed on a device from IME Technologies with rotating drum collector and climate chamber. A $1.2 \mathrm{~g}$ sample of poly(vinyl alcohol) (PVA, from Bratachem) and $400 \mathrm{mg}$ of iridium(III) choride-hydrate (from Strem Chemicals Inc.) were dissolved in $\mathrm{N}, \mathrm{N}$-dimethylacetamide (DMAc, from Carl Roth) to give a $10 \mathrm{wt} \%$ solution with respect to the polymer. The solution was stirred for $12 \mathrm{~h}$ at $140{ }^{\circ} \mathrm{C}$ and cooled to ambient temperature before the electrospinning process was initialized. The precursor nanofibers were fabricated in a $14 \mathrm{kV}$ electric field with a tip-to-collector distance of $15 \mathrm{~cm}$; the flow rate of solution was fixed at $90 \mu \mathrm{L} / \mathrm{h}$. After successful electrospinning, the nanofiber mat was placed in an oven under an ambient atmosphere and heated to $370{ }^{\circ} \mathrm{C}$ for $4 \mathrm{~h}$ with a heating rate of $1 \mathrm{~K} / \mathrm{min}$. The result was a brittle IrOx nanofiber mat, which could be directly used for ink preparation, as it collapses into individual fibers during the following ultrasonication step.

MEA Fabrication. Two different inks were prepared containing IrOx catalyst in 40 wt \% Nafion D520 dispersion in a 1:1 DI water to isopropanol solution, as reported in an earlier work. ${ }^{23}$ The IrOx nanoparticle inks contained 1 wt \% solids (Alfa Aesar iridium(IV) oxide, Premion) while the $\mathrm{IrOx}$ nanofiber inks contained 0.5 wt \% solids. All suspensions were ultrasonicated for $30 \mathrm{~min}$ before use. Both the nanoparticle catalyst and nanofiber interlayer were deposited via spray-coating directly onto half catalyst coated membranes with 0.5 $\mathrm{mg}_{\mathrm{pt}} \mathrm{Pt} / \mathrm{C}$ cathodes and Nafion N115 ( $\sim 125 \mu \mathrm{m}$ thickness $)$ and Nafion NR 212 membranes ( $\sim 50 \mu \mathrm{m}$ thickness). For spray-coating a benchtop ultrasonic spray coater (Sonocell SNR-300) equipped with a $130 \mathrm{kHz}$ ultrasonic nozzle was applied. The coating was conducted in an intercrossed pattern with $1.5 \mathrm{~mm}$ pitch between the spray paths. The spray head speed was adjusted to $170 \mathrm{~mm} / \mathrm{s}$, the ink flow rate to $0.35 \mathrm{~mL} / \mathrm{min}$, and the hot plate temperature to $90{ }^{\circ} \mathrm{C}$. The Ir loading was determined by weighing a reference substrate in a high precision scale (Sartorius ME-36S) and correcting to the pure iridium content. While the reference anodes where sprayed in one process step, the nanofiber interlayer MEAs were fabricated by first spraying a loading of $0.1 \mathrm{mg}_{\mathrm{II}} / \mathrm{cm}^{2}$ nanoparticles onto the membrane and further depositing $0.1 \mathrm{mg}_{\mathrm{Ir}} / \mathrm{cm}^{2}$ nanofibers on top.

Crystallography. X-ray diffraction (XRD) patterns were measured in a Bruker D8 Advance diffractometer (Bruker AXS, $\mathrm{Cu} \mathrm{K} \alpha$ radiation) between $20^{\circ}$ and $80^{\circ} 2 \theta$ with an increment of $0.05^{\circ}$ and a measuring time of $6 \mathrm{~s}$ per step.

Nitrogen Adsorption Analysis. $\mathrm{N}_{2}$ physisorption isotherms were obtained at $77 \mathrm{~K}$ by using an Autosorb-1 (Quantachrome). The samples were initially filled in a glass tube; to reduce the dead volume, a glass rod and glass wool were inserted. The samples were degassed under vacuum at $90{ }^{\circ} \mathrm{C}$ for $24 \mathrm{~h}$ to remove adsorbed gas. Adsorption and desorption isotherms were recorded in a range of $10^{5} \leq p / p_{0} \leq$ 0.995 with $p_{0}$ being the saturation pressure and $p$ the gas pressure. The Brunauer-Emmett-Teller (BET) method $^{24}$ was applied to evaluate the overall surface area. A multipoint fit was used in the range of $0.1 \leq p / p_{0} \leq 0.3$.

In-Plane Resistivity. The sheet resistance of the catalyst layers was determined by a transfer line method using a similar setup as Ahadi et al. ${ }^{25}$ Catalyst films with a width of $1 \mathrm{~cm}$ were prepared by spray-coating onto an insulating glass substrate. Carbon paper with a microporous layer (MPL) (Freudenberg $\mathrm{H} 24 \mathrm{C} 5$ ) and a width of 5 $\mathrm{mm}$ was pressed with $0.7 \mathrm{~N}$, MPL-side first, onto the film, to electronically contact the entire width of the film. The resistance was measured for contact distances of $1,2,3$, and $4 \mathrm{~cm}$ at ambient conditions $\left(25^{\circ} \mathrm{C}, 50 \% \mathrm{RH}\right)$ by using a FLUKE 175 multimeter. By plotting the resistance against the distance between measuring points and fitting linearly, we determined the sheet resistance from the slope. Thus, we define the electronic in-plane resistance reported in this work as $R_{\text {sheet }}=\mathrm{d} R / \mathrm{d} x \cdot w$, where $R$ is the measured ohmic resistance, $w$ is the width, and $x$ is the measuring distance between the contact points of the test sample.

Rotating-Disk Electrode. The experiments were conducted in a three-electrode cell with a catalyst loading of $17.8 \mu \mathrm{g} / \mathrm{cm}^{2}$ on a glassy carbon electrode in $\mathrm{N}_{2}$-purged $0.05 \mathrm{M} \mathrm{H}_{2} \mathrm{SO}_{4}$ with an electrode rotation of $1600 \mathrm{rpm}$. Cyclic voltammetry $(\mathrm{CV})$ was conducted between 0.35 and $1.4 \mathrm{~V}$ at a scan rate of $50 \mathrm{mV} / \mathrm{s}$. The charge was obtained by averaging the integral of the anodic and cathodic sweeps. 
The OER activity was evaluated by sweeping the potential from $1.0 \mathrm{~V}$ to the potential where $10 \mathrm{~mA} / \mathrm{cm}^{2}$ was reached with $5 \mathrm{mV} / \mathrm{s}$. All potentials are reported vs RHE, and the results were averaged over six measurements.

Electron Microscopy and Energy-Dispersive X-ray Spectroscopy. To investigate morphology and material composition electron microscopy and energy-dispersive X-ray spectroscopy (EDX) were conducted in a FEI Scios 2 focused ion beam scanning electron microscope (FIB-SEM) with an AMETEK EDAX Elite Super EDX detector. The scanning electron microscopy images were recorded with an acceleration voltage of $5 \mathrm{kV}$. The material composition was determined in the EDX at $30 \mathrm{kV}$.

Polarization Curves. Cell polarization was measured in a $5 \mathrm{~cm}^{2}$ single cell setup by using a Scribner 857 redox flow potentiostat. The cell was operated at ambient pressure, $80{ }^{\circ} \mathrm{C}$, and a deionized water flow rate of $40 \mathrm{~mL} / \mathrm{min}$ at the anode and cathode side. A sintered titanium fiber PTL (Bekaert 2GDL40-1.0) was used on the anode side and a carbon paper (Freudenberg H24C5) on the cathode side. On both sides, gold-coated parallel type titanium flow fields with 5 $\mathrm{cm}^{2}$ area, $1 \mathrm{~mm}$ channel width, and $1 \mathrm{~mm}$ land width were applied. The high frequency resistance (HFR) free voltage was measured during polarization measurement at $1 \mathrm{kHz}$. Polarization curves were obtained by holding constant current steps of $120 \mathrm{~s}$ for the N115 MEAs and $30 \mathrm{~s}$ for the N212 MEAs.

Accelerated Stress Tests. Accelerated stress testing (AST) was conducted according to a protocol suggested by Spöri et al., ${ }^{9}$ which is partly based on the results of Cherevko et al. ${ }^{26,27}$ The AST protocol varies the voltage between 0.05 and $1.4 \mathrm{~V}$ in square wave cycles $(3 \mathrm{~s}$ each potential) and was designed to achieve a maximum dissolution rate of $\mathrm{IrOx}$. Enhanced Ir dissolution was observed during transient operation compared to prolonged galvanostatic holds by using a scanning flow cell coupled with an inductively coupled plasma mass spectrometer. The highest dissolution rates were obtained at upper potential limits of $1.3-1.4 \mathrm{~V} .^{27}$ The ASTs where conducted in the same $5 \mathrm{~cm}^{2}$ single cell setup used for the polarization measurements. The cell was also operated at ambient pressure, $80^{\circ} \mathrm{C}$ and a flow rate of $40 \mathrm{~mL} / \mathrm{min}$ for the anode and cathode side. The conductivity of the process water was measured, and the water was replaced every 24 $\mathrm{h}$ to ensure low ion contamination confirmed by conductivity values below $3 \mu \mathrm{S} / \mathrm{cm}$. Prior to the AST the cell was cycled until a stable cell operation was observed, since in the case of the nanoparticle MEA initial cycling led to a performance improvement, possibly due to a promoted porosity by initial dissolution. ${ }^{9}$ Cell polarization was measured after 5000, 14000, and 40000 AST cycles.

Constant Current Holds. Constant current holds were conducted at $2 \mathrm{~A} / \mathrm{cm}^{2}$, ambient pressure, $80{ }^{\circ} \mathrm{C}$, and a flow rate of $40 \mathrm{~mL} / \mathrm{min}$ for the anode and cathode side. Cell polarization curves were measured at the beginning and every $50 \mathrm{~h}$. The process water was replaced every $24 \mathrm{~h}$ to ensure low ion contamination.

\section{RESULTS AND DISCUSSION}

Materials Characterization. As the catalytic activity largely depends on the material composition, the nanofibers and nanoparticles used in this study were analyzed with energy-dispersive X-ray spectroscopy (EDX). The EDX measurements yield a mass composition of $85 \%$ Ir and $15 \%$ $\mathrm{O}_{2}$ for the IrOx nanofibers, corresponding to the weight fractions of pure $\mathrm{IrO}_{2}$. The composition of the commercial Alfa Aesar nanoparticles was measured to be $79 \% \mathrm{Ir}$ and $21 \% \mathrm{O}_{2}$. Excess oxygen of the Alfa Aesar IrOx was also reported by Pfeiffer et al. ${ }^{28}$ and can be attributed to a surface hydration. Besides the composition, also crystallinity has a strong effect on the activity. ${ }^{29-33}$ Therefore, X-ray diffraction (XRD) patterns were measured (Figure 1). The sharp reflections at $40.8^{\circ}, 47.4^{\circ}$, and $69^{\circ}$ found in both samples can be assigned to a metallic iridium phase, ${ }^{34}$ the mean crystallite size of which appears smaller for the nanofibers as indicated by the broader reflections. $^{35}$ The pattern of the commercial Alfa Aesar

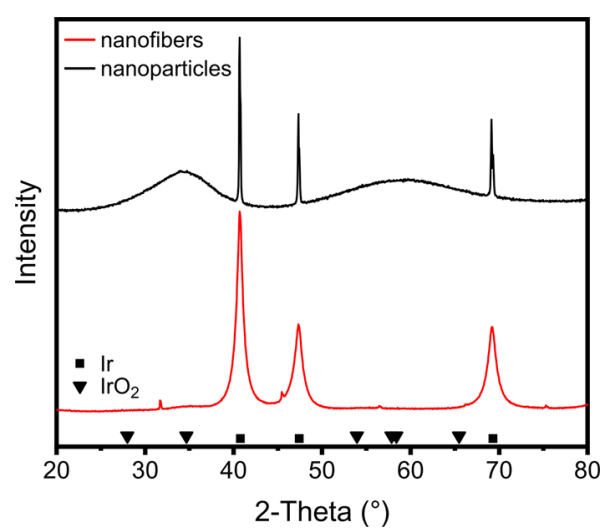

Figure 1. X-ray diffraction patterns of the IrOx nanofibers (red pattern) and the commercial Alfa Aesar IrOx nanoparticles (black pattern). Characteristic locations of Bragg reflections of Ir (squares) and $\mathrm{IrO}_{2}$ (lower triangles) are indicated at the bottom.

nanoparticles is fully consistent with earlier reports. ${ }^{28}$ The significant amount of oxygen, as seen in both EDX measurements, indicates an oxide phase in addition to the metallic iridium phase. In the XRD pattern, the $\mathrm{IrO}_{2}$ reflections of the nanofibers are either absent or too broad to see, while the nanoparticles show weak broad $\mathrm{IrO}_{2}$ reflections. Thus, the oxide phase is rather amorphous for both samples. ${ }^{29}$

The electrochemical activity is further governed by the electrochemically active surface areas (ECSA). Even though the ECSAs cannot be accurately estimated from the capacitive charge under $\mathrm{CV}$ measurements for metal oxides, ${ }^{36}$ the charge can be used to qualitatively compare the active surface area, when material and sample loading are similar. When estimated from the area of the cyclic voltammograms (Figure 2a), the normalized interfacial charge of the nanoparticles $(4.2 \pm 0.7$ $\left.\mathrm{mC} / \mathrm{cm}^{2}\right)$ is $\sim 7$ times higher than that of the nanofiber sample $\left(0.6 \pm 0.2 \mathrm{mC} / \mathrm{cm}^{2}\right)$. A larger surface area of the $\mathrm{IrOx}$ nanoparticles is also observed in BET measurements, which yield $57 \mathrm{~m}^{2} / \mathrm{g}$ for the nanoparticles and only $28 \mathrm{~m}^{2} / \mathrm{g}$ for the nanofibers (Figure 2c). The difference between the CV and the BET measurements could be explained by the additional dependency of the charge from the IrOx calcination temperature. $^{26}$ Rotating disk electrode (RDE) measurements show that the required potentials to reach $10 \mathrm{~mA} / \mathrm{cm}^{2}$ (geometric area) are $1.65 \pm 0.01 \mathrm{~V}$ for the nanoparticles and $1.67 \pm 0.03$ $\mathrm{V}$ for the nanofibers (Figure $2 \mathrm{~b}$ ). Thus, the nanoparticles have a higher geometric activity with the catalyst loading (both 17.8 $\mu \mathrm{g} / \mathrm{cm}^{2}$ ), which can be explained by a higher surface area due to their spherical shape and smaller particle size (Figure 3a,b). The nanofibers are in the range of 50-400 $\mathrm{nm}$ in diameter and $1-3 \mu \mathrm{m}$ in length (Figure $3 \mathrm{~b}$ ), while the mean agglomerate diameter of the nanoparticles is $\sim 100 \mathrm{~nm} .{ }^{37}$ The electrochemical results obtained with the RDE and additional activity metrics are summarized in Table 1 . As shown in the table, the mass activity of the nanoparticles at $1.6 \mathrm{~V}$ is $45 \%$ higher than the activity of the nanofibers, which again can be attributed to their higher surface area.

With this in mind, morphological properties of conventional nanoparticle catalyst layers and those with nanofiber interlayer shall be investigated. As discussed in the Introduction, recent studies show that the in-plane conductivity and connectivity of the particles have a strong effect on the overall performance of the catalyst layer. To quantify the in-plane conductivity, the electronic sheet resistances were determined for both layers. As 


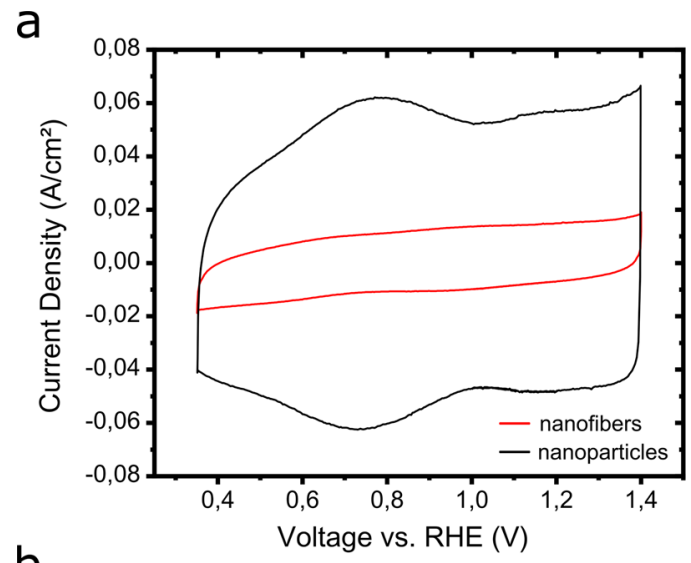

b

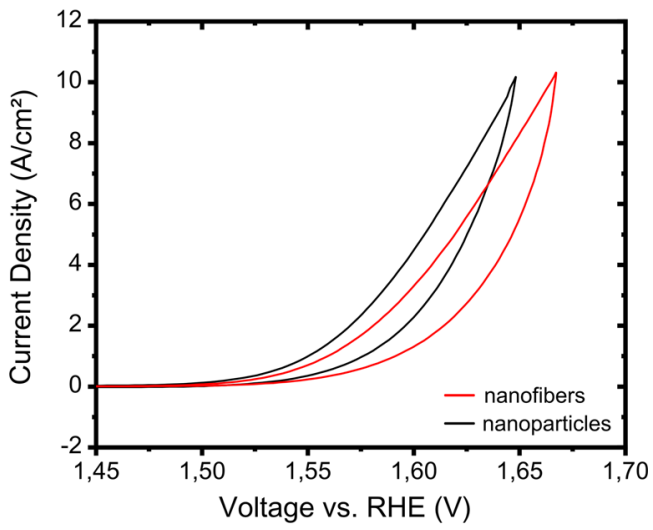

C

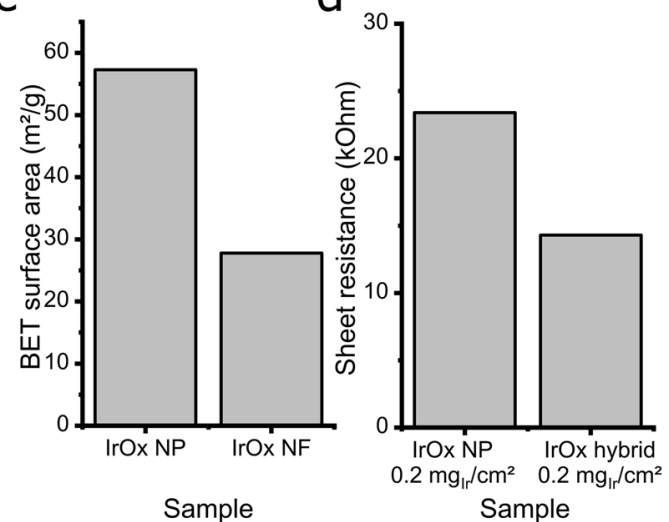

Figure 2. Cyclic voltammograms (a) and OER activity (b) of IrOx nanoparticles and $\mathrm{IrOx}$ nanofibers, measured on a rotating disc electrode in $0.05 \mathrm{M} \mathrm{H}_{2} \mathrm{SO}_{4}$ with a rotation speed of $1600 \mathrm{rpm}$. (c) BET surface area of the IrOx particles and the IrOx nanofibers. (d) Sheet resistance of an $\mathrm{IrOx}$ nanoparticle sample compared to an $\mathrm{IrOx}$ hybrid sample ( $\mathrm{IrOx}$ nanofiber interlayer on $\mathrm{IrOx}$ nanoparticles) measured in ambient air. Both samples were prepared by spraycoating the catalyst materials on a glass substrate with a total loading of $0.2 \mathrm{mg}_{\mathrm{Ir}} / \mathrm{cm}^{2}$.

shown in Figure 2d, the sheet resistance of an IrOx particle layer with nanofiber interlayer is significantly lower than that of the pure IrOx particles, although both samples have the same total IrOx loading of $0.2 \mathrm{mg}_{\mathrm{Ir}} / \mathrm{cm}^{2}$. It is to note that the samples for the conductivity measurements were deposited on a glass substrate. Even though the same spray parameters were used as for MEA fabrication, the wettability of the substrate can have a significant impact on the morphology of the formed layer. Moreover, the conductivity of both samples was
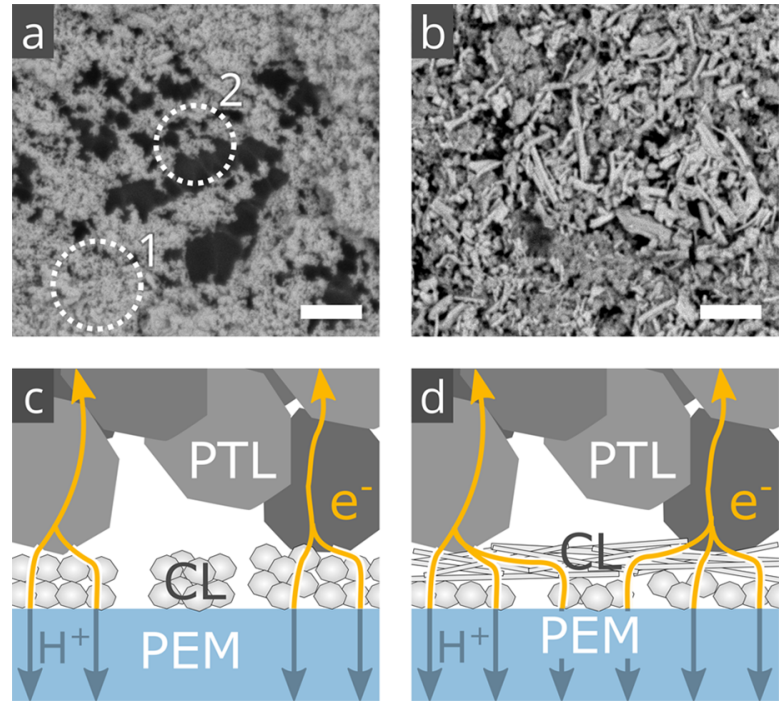

Figure 3. (a) Top view on low loaded $\left(0.2 \mathrm{mg}_{\mathrm{Ir}} / \mathrm{cm}^{2}\right)$ nanoparticle catalyst layer with representative homogeneous region (1) and some electronically disconnected islands (2). Scale bar is $2 \mu \mathrm{m}$. (b) Top view on nanofiber interlayer of the IrOx hybrid anode with nanoparticle catalyst layer visible in background. Total loading is $0.2 \mathrm{mg}_{\mathrm{Ir}} / \mathrm{cm}^{2}$. The scale bar is $2 \mu \mathrm{m}$. Both catalyst layers were deposited on Nafion N115 membranes. (c) Schematic of a low loaded catalyst layer $(\mathrm{CL})$ with catalyst that is electronically disconnected from the porous transport layer (PTL). (d) Schematic of the hybrid IrOx anode comprising a low loaded CL with nanofiber interlayer that distributes electrons to all regions of the $\mathrm{CL}$ and enhances stability.

Table 1. Summary of the RDE Results Measured in $0.05 \mathrm{M}$ $\mathrm{H}_{2} \mathrm{SO}_{4}$ with a Catalyst Loading of $17.8 \mu \mathrm{g} / \mathrm{cm}^{2}$ : Potential to Reach $10 \mathrm{~mA} / \mathrm{cm}^{2}$ (Geometric Area), Normalized Charge $(Q)$, and Various Metrics at 1.6 V (Geometric Surface Area $j_{\text {geo }}$, Mass-Based $j_{\text {mass }}$, and BET Specific Activity $j_{\text {spec }}$ )

\begin{tabular}{lll} 
& \multicolumn{1}{c}{ Ir NP } & \multicolumn{1}{c}{ Ir NF } \\
$E$ at $10 \mathrm{~mA} / \mathrm{cm}^{2}{ }_{\text {geo }}(\mathrm{V})$ & $1.65 \pm 0.01$ & $1.67 \pm 0.03$ \\
$Q\left(\mathrm{mC} / \mathrm{cm}^{2}\right)$ & $4.2 \pm 0.7$ & $0.6 \pm 0.2$ \\
$j_{\text {geo }}$ at $1.6 \mathrm{~V}\left(\mathrm{~mA} / \mathrm{cm}^{2}\right)$ & 4.5 & 3.3 \\
$j_{\text {mass }}$ at $1.6 \mathrm{~V}\left(\mathrm{~A} / \mathrm{g}_{\mathrm{Ir}}\right)$ & 318 & 219
\end{tabular}

measured in dry conditions. In electrolysis operation, the wetting of the ionomer decreases the conductivity of the catalyst layer. This effect is due to swelling and thus additional spatial separation of the catalyst material. ${ }^{13}$ Because both samples are affected in a similar way, we assume a similar outcome in electrolysis operation.

The morphology of both catalyst layers (CL) is depicted in Figure 3, where Figure 3a shows the top view of the ultralow loaded $\left(0.2 \mathrm{mg}_{\mathrm{Ir}} / \mathrm{cm}^{2}\right)$ nanoparticle anode. The IrOx nanoparticle catalyst layer mostly contains regions with a homogeneous coating (1) but also certain regions, where the catalyst material is electronically disconnected from the rest of the catalyst layer (2). This observation confirms the recent findings of Bernt et al., ${ }^{12}$ reporting disconnected islands in lowloading anode catalyst layers. As shown in Figure 3b, the nanofiber interlayer of the hybrid anode (total loading including the interlayer is $0.2 \mathrm{mg}_{\mathrm{Ir}} / \mathrm{cm}^{2}$ ) contains fibers with diameters in the range 50-400 $\mathrm{nm}$ and lengths in the range 1$3 \mu \mathrm{m}$. The particle layer is visible through the nanofiber interlayer, indicating high porosity and low total layer thickness. In contrast to the pure nanoparticle CL, the hybrid 
CL contained no disconnected regions, which is a potential indication for the stabilizing effect of the nanofibers on very thin layers.

Figure 3c,d shows schematic representations of the observed effects. As the pure nanoparticle CL contains electrically disconnected regions, this catalyst material does not contribute to the overall performance, which also constricts the proton flow in the membrane. In the case of the hybrid CL, the nanofiber interlayer connects all regions increasing the overall utilization. The lower sheet resistance was a first indication for this theory. However, to further elucidate this, the electrochemical performance of both layers was evaluated in depth.

Electrochemical Performance. The performance of the low loaded $\mathrm{IrOx}$ hybrid MEA was compared in cell polarization tests against three reference MEAs, two with identical loading $\left(0.2 \mathrm{mg}_{\mathrm{Ir}} / \mathrm{cm}^{2}\right.$, pure nanoparticle and pure nanofiber) and one with a high anode loading $\left(1.2 \mathrm{mg}_{\mathrm{Ir}} / \mathrm{cm}^{2}\right)$ as a state-of-the-art performance benchmark. As shown in Figure 4a, the low
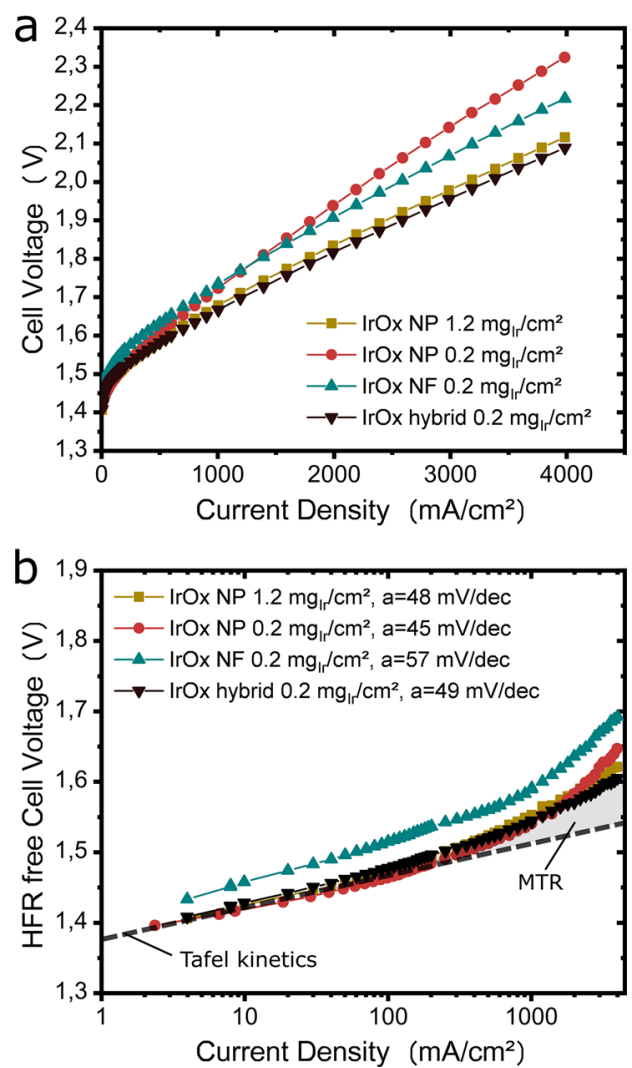

Figure 4. Comparison of cell polarization (a) and Tafel plot of the HFR free polarization curves (b) of the $0.2 \mathrm{mg}_{\mathrm{Ir}} / \mathrm{cm}^{2}$ hybrid MEA (nanofibers on nanoparticle anode) vs equally manufactured reference MEAs with $0.2 \mathrm{mg}_{\mathrm{Ir}} / \mathrm{cm}^{2}$ pure nanofiber (NF) anode, $0.2 \mathrm{mg} / \mathrm{cm}$ nanoparticle (NP) anode, and nanoparticle anode with state-of-the-art loading of $1.2 \mathrm{mg}_{\mathrm{II}} / \mathrm{cm}^{2}$. All MEAs are based on Nafion $\mathrm{N} 115$ membranes and measured at ambient pressure and a temperature of $80{ }^{\circ} \mathrm{C}$ in a $5 \mathrm{~cm}^{2}$ cell. The Tafel slope $a$ was determined between 10 and $100 \mathrm{~mA} / \mathrm{cm}^{2}$

loaded nanoparticle MEA performed significantly worse than the high loaded reference MEA, featuring a cell voltage of 2.12 $\mathrm{V}$ (70\% voltage efficiency) compared to $2.32 \mathrm{~V}$ (64\% voltage efficiency) at $4 \mathrm{~A} / \mathrm{cm}^{2}$. A major part of the losses is caused by an increased high frequency resistance (HFR). The higher HFR potentially stems from an increased membrane resistance due to a reduced effective membrane cross section for the proton transport and a higher contact resistance between the CL and the PTL because of less contact. This current constriction is a consequence of an uneven activity distribution, which is caused by the poor in-plane electron conductivity of the low loaded CL. This effect of nonuniform activity distribution with high activities in regions close to the PTL metal (Figure 3c) was first found by Mo et al. ${ }^{38}$ and investigated for low loaded anodes by Bernt et al. ${ }^{12}$

To compare kinetic effects, Tafel plots of the HFR free cell potential were analyzed (Figure $4 \mathrm{~b}$ ). The similar Tafel slopes (depicted by the dashed line) indicate only marginal differences in kinetics of the low loaded and the high loaded MEA. Hence, for the IrOx nanoparticle MEAs, investigated in this work, a difference in kinetic activity does not cause the low performance when reducing the loading. Experimental results from the literature show increased kinetic overpotentials for ultralow loadings ${ }^{12}$ for some catalysts but in other cases no significant change in kinetic overpotentials ${ }^{15,39,39}$ even when the loading was decreased to values as low as $0.1 \mathrm{mg} / \mathrm{cm}^{2}$. Thus, we conclude that the influence of kinetics when reducing the loading plays only a minor role especially for highly active catalyst materials and is decisively depending on the properties of the catalyst. Besides the increased HFR, we assume that the uneven activity distribution is also responsible for the increased mass transport loss due to increased local fluxes. The mass transport losses can be estimated by the difference between the extrapolated Tafel fit and the HFR free cell voltage ${ }^{40}$ as depicted by the gray area in Figure $4 \mathrm{~b}$. It is to note that this estimation also includes the proton transport losses in the CL, which however are assumed to have a minor effect due to the small thickness of the low loaded anodes. ${ }^{41,42}$ With $125 \mathrm{mV}$ vs $80 \mathrm{mV}$ at $4 \mathrm{~A} / \mathrm{cm}^{2}$, the mass transport overpotential of the low loaded reference MEA is significantly higher in comparison to the $1.2 \mathrm{mg}_{\mathrm{Ir}} / \mathrm{cm}^{2}$ MEA.

When moving from the low loaded pure nanoparticle to a pure nanofiber MEA, a significant reduction of the overpotentials is achieved (Figure 4a). The HFR is comparable to the high loaded reference MEA, which we attribute to the higher conductivity due to better connection of the nanofibers compared to the particles. The mass transport overpotential is with $91 \mathrm{mV}$ at $4 \mathrm{~A} / \mathrm{cm}^{2}$ significantly lower compared to the equally loaded particle reference. Besides the good connection of the nanofibers, the reduction of mass transport resistance (MTR) possibly stems from a more porous CL structure. However, the kinetics of the nanofiber anode are worse as observed in the low current density region of the Tafel plot (Figure $4 b$ ). The worse kinetics of the pure nanofiber catalyst layer is in line with the lower ECSA and the lower activity (especially in the low current density region) in $\mathrm{RDE}$ measurements as discussed in the Materials section.

Applying a nanofiber interlayer on top of an ultralow loaded particle anode $\left(0.1 \mathrm{mg}_{\mathrm{Ir}} / \mathrm{cm}^{2}\right.$ nanofibers and $0.1 \mathrm{mg} / \mathrm{cm}^{2}$ nanoparticles) combines the advantages of the nanoparticles, i.e., high activity and ECSA, and the nanofibers, i.e., high conductivity and low mass transport resistance. Furthermore, the highly active nanoparticles are closely located to the membrane interface, which is in general assumed to be the region with the highest activity in through-plane direction. ${ }^{43}$ In fact, the MEA prepared in this fashion yields the best performance and even outperforms the $1.2 \mathrm{mg} / \mathrm{cm}^{2}$ nanoparticle MEA (Figure 4a,b). 
To confirm the excellent performance of the low loaded interlayer MEAs, the results were compared to the state-of-theart performance range, gathered from $\sim 200$ publications in a recent study by Bender et al. ${ }^{44}$ In addition to the Nafion 115 MEA (Figure 5a), a Nafion NR 212 MEA was fabricated and
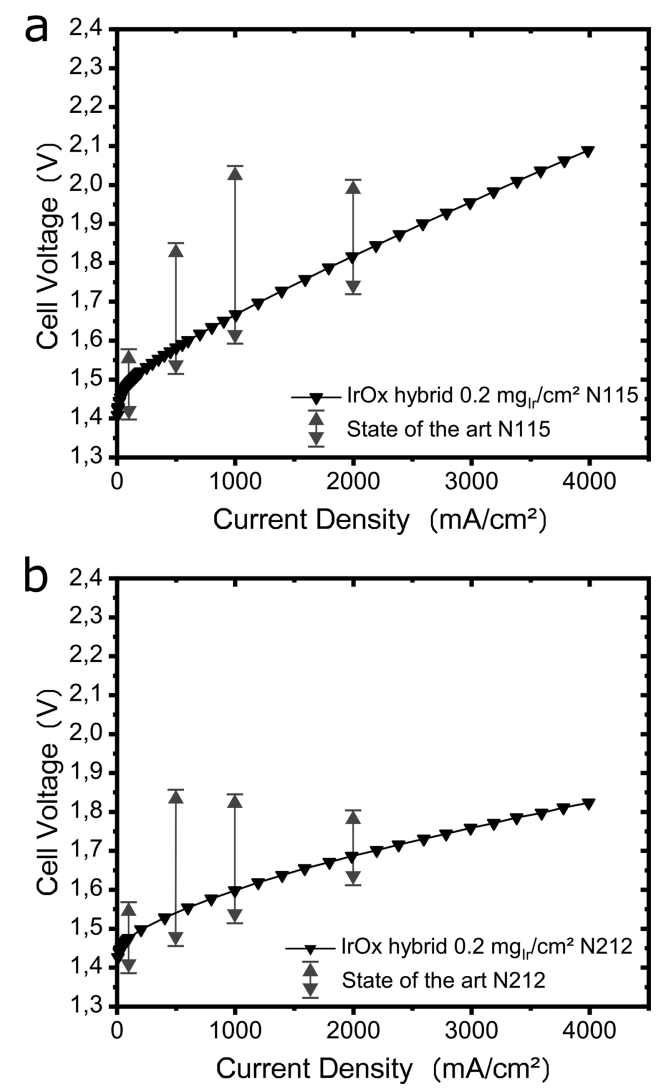

Figure 5. Comparison of cell polarization curves of the $0.2 \mathrm{mg}_{\mathrm{Ir}} / \mathrm{cm}^{2}$ hybrid MEA on a Nafion 115 membrane (a) and on a Nafion 212 membrane (b) vs state-of-the-art performance ranges of PEMWE cells $^{44}$ for identical membrane type and operating conditions of $80^{\circ} \mathrm{C}$ and ambient pressure. It is to note that the literature data in this comparison also contain values from MEAs with highly active mixed oxide and supported catalysts with loadings $>1 \mathrm{mg} / \mathrm{cm}^{2}$, while the hybrid MEAs of this study used pure IrOx.

included in the comparison (Figure $5 b$ ). It should be noted that the reported cell performance values significantly deviate from each other due to different catalyst material compositions (e.g., Ir-Ni, Ir-Co, IrRuOx, etc.), high Ir loadings (beyond 1 $\mathrm{mg} / \mathrm{cm}^{2}$ ), and cell assemblies including performance enhancing measures like pretreating the membrane or sputter coating the porous transport layers. With this in mind, it is even more astonishing that despite the simple IrOx catalyst material and the ultralow loading used in this study, the polarization curves are close to the most active region of the state-of-the-art cell voltage range, demonstrating the very competitive performance of the present ultralow loaded hybrid MEAs.

Durability. Besides performance, durability of the anode is vital for long-term operation of the PEM water electrolyzer. To support the theory of the stabilizing effect of the nanofiber interlayer (see the Introduction), accelerated stress tests (ASTs) were performed. The applied AST protocol was chosen to achieve a maximum iridium dissolution. ${ }^{9}$ Because the protocol was originally developed for RDE measurements and the voltage was significantly lower than in typical electrolyzer operation, additional constant current holds at 2 $\mathrm{A} / \mathrm{cm}^{2}$ were performed. Figure $6 \mathrm{a}$ shows the cell polarization
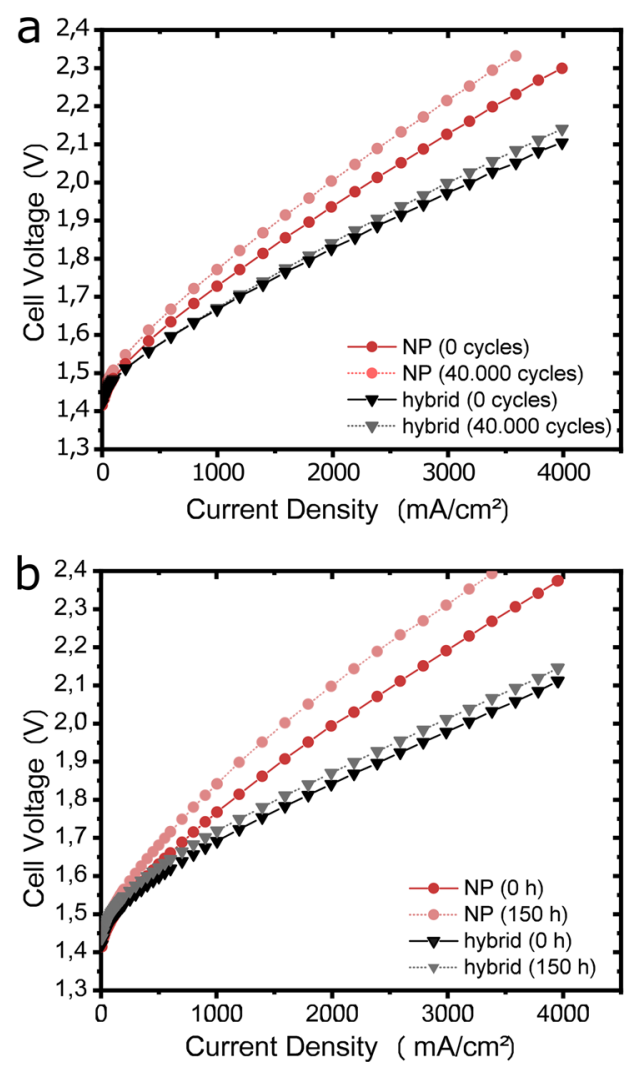

Figure 6. (a) Comparison of cell polarization curves of the $0.2 \mathrm{mg} /$ $\mathrm{cm}^{2} \mathrm{IrOx}$ hybrid MEA vs a $0.2 \mathrm{mg} / \mathrm{cm}^{2}$ nanoparticle MEA before and after 40000 AST cycles. (b) Comparison of cell polarization curves of the $0.2 \mathrm{mg} / \mathrm{cm}^{2}$ IrOx hybrid MEA vs a $0.2 \mathrm{mg} / \mathrm{cm}^{2}$ nanoparticle MEA before and after $150 \mathrm{~h}$ constant current hold at $2 \mathrm{~A} / \mathrm{cm}^{2}$. Both MEAs are based on Nafion 115 membranes.

curves of the ultralow loaded IrOx hybrid MEA and the ultralow loaded nanoparticle MEA before and after 40000 AST cycles. Figure $6 \mathrm{~b}$ shows the cell polarization curves of identically prepared samples before and after $150 \mathrm{~h}$ constant current holds at $2 \mathrm{~A} / \mathrm{cm}^{2}$.

After both durability tests, the overvoltage of the hybrid MEAs is significantly lower than the overvoltage of the aged nanoparticle MEAs. At a current density of $2 \mathrm{~A} / \mathrm{cm}^{2}$ the hybrid MEA shows a minimal performance loss of $14 \mathrm{mV}$ over 40000 AST cycles (Figure 6a). In contrast, the nanoparticle MEA shows a significant performance loss, with a voltage increase of $68 \mathrm{mV}$. The overvoltages after the constant current holds confirm the higher stability of the hybrid MEA. The voltage of the low loaded nanoparticle layer significantly increased by 104 $\mathrm{mV}$ after $150 \mathrm{~h}$ of constant current hold at $2 \mathrm{~A} / \mathrm{cm}^{2}$, while the hybrid MEA shows a voltage drop of $29 \mathrm{mV}$ (Figure $6 \mathrm{~b}$ ). The average voltage degradation rates are $0.2 \mathrm{mV} / \mathrm{h}$ for the hybrid MEA and $0.7 \mathrm{mV} / \mathrm{h}$ for the NP MEA (Figure S1). The higher stability of the hybrid layer MEA in comparison to the nanoparticle MEA seems surprising due to the similar IrOx type used in both samples. However, as discussed in the Introduction, the dissolution rates not only depend on the crystallinity but also on the morphology of the catalyst layer. It is assumed that besides the material properties, also surface area, porosity, mass transport, and electron and proton 
conductivity have an impact on the durability. ${ }^{44}$ The conducted stability tests indicate a higher stability of the hybrid CCM compared to equally loaded particle CCMs. However, to fully understand the reasons for the higher stability of the hybrid CCM, extensive material characterization should be conducted in future studies.

\section{CONCLUSIONS}

We present an IrOx nanofiber interlayer anode for PEM water electrolysis. With this novel anode architecture, we were able to reduce the iridium loading by more than $80 \%$ in comparison to a state-of-the-art $\mathrm{IrOx}$ anode while maintaining performance and durability. We showed that superior performance is achieved by combining the advantage of good electric contact and high porosity of the IrOx nanofibers with high surface area of IrOx nanoparticles. To investigate the advantages of the nanofiber interlayer anode, nanoparticles and nanofibers where characterized with respect to composition, crystallinity, catalyst surface area, conductivity, and microstructure. EDX measurements showed a similar composition, and XRD spectra exhibited a predominantly amorphous crystal structure for both samples, indicating that the major part of the performance differences in fact have to stem from the particular morphologies of the anodes. The catalyst surface area of the IrOx nanoparticles was found to be significantly higher than that of the nanofibers, as determined by BET analysis with 57 and $28 \mathrm{~m}^{2} / \mathrm{g}$, respectively. The ex-situ sheet resistance of a nanofiber/nanoparticle hybrid anode was found to be significantly lower than that of a pure nanoparticle anode, indicating an improved electric contact of the catalyst fibers. The better connectivity of the catalyst material was also observed in SEM images. In contrast to an equally loaded ( 0.2 $\mathrm{mg}_{\mathrm{Ir}} / \mathrm{cm}^{2}$ ) IrOx nanoparticle anode, the nanofiber interlayer anode exhibited no electrically isolated islands. In polarization experiments CCMs with $\mathrm{IrOx}$ nanofiber interlayer anodes with a loading of $0.2 \mathrm{mg}_{\mathrm{Ir}} / \mathrm{cm}^{2}$ outperformed equally fabricated state-of-the-art nanoparticle MEAs with 0.2 and $1.2 \mathrm{mg}_{\text {Ir }} / \mathrm{cm}^{2}$ loading as well as $0.2 \mathrm{mg}_{\mathrm{Ir}} / \mathrm{cm}^{2}$ pure IrOx nanofiber MEAs. In comparison to state-of-the-art performance of higher loaded MEAs from the literature, the nanofiber interlayer MEAs showed above average performance. Besides performance, durability was assessed by accelerated stress tests and constant current holds at $2 \mathrm{~A} / \mathrm{cm}^{2}$. While an equally loaded nanoparticle MEA showed a significant performance loss of $68 \mathrm{mV}$ at $2 \mathrm{~A} /$ $\mathrm{cm}^{2}$, the overvoltage of the hybrid MEA increased by only 14 $\mathrm{mV}$ over the complete test length of 40000 cycles. The results of the constant current holds confirmed the improved stability of the hybrid MEA with an average voltage degradation of 0.2 $\mathrm{mV} / \mathrm{h}$ at $2 \mathrm{~A} / \mathrm{cm}^{2}$ over $150 \mathrm{~h}$ vs $0.7 \mathrm{mV} / \mathrm{h}$ for the nanoparticle MEA.

The improved performance can be attributed to combining the advantages of nanofibers and nanoparticles. The high porosity and the good electrical and mechanical contact of the IrOx nanofibers lead to low mass transport losses and high catalyst utilization, while the $\mathrm{IrOx}$ nanoparticles contribute with high surface area and activity.

In this work, we intended to demonstrate the advantages of the electrode structure of the nanofiber interlayer anodes. Therefore, pure IrOx was used as a simple and established anode material. In future studies mixed oxides and iridium based alloys with higher activity or smaller IrOx nanoparticles with an increased surface area can be used to even further increase the performance or durability of the novel hybrid catalyst layer architecture.

\section{ASSOCIATED CONTENT}

\section{Supporting Information}

The Supporting Information is available free of charge at https://pubs.acs.org/doi/10.1021/acsaem.0c00735.

Voltage evolution over time during $150 \mathrm{~h}$ constant current hold of $0.2 \mathrm{mg} / \mathrm{cm}^{2}$ IrOx hybrid MEA and 0.2 $\mathrm{mg} / \mathrm{cm}^{2}$ nanoparticle (NP) MEA (PDF)

\section{AUTHOR INFORMATION}

\section{Corresponding Authors}

Severin Vierrath - Electrochemical Energy Systems, IMTEK Department of Microsystems Engineering, University of Freiburg, 79110 Freiburg, Germany; Hahn-Schickard, 79110 Freiburg, Germany; ○ orcid.org/0000-0002-4505-2803;

Email: severin.vierrath@imtek.de

Peter Strasser - The Electrochemical Energy, Catalysis, and Materials Science Group, Department of Chemistry, Technical University Berlin, 10623 Berlin, Germany; 이 orcid.org/00000002-3884-436X; Email: pstrasser@tu-berlin.de

\section{Authors}

Friedemann Hegge - Electrochemical Energy Systems, IMTEK - Department of Microsystems Engineering, University of Freiburg, 79110 Freiburg, Germany

Florian Lombeck - Hahn-Schickard, 79110 Freiburg, Germany Edgar Cruz Ortiz - Electrochemical Energy Systems, IMTEK Department of Microsystems Engineering, University of Freiburg, 79110 Freiburg, Germany

Luca Bohn - Electrochemical Energy Systems, IMTEK Department of Microsystems Engineering, University of Freiburg, 79110 Freiburg, Germany

Miriam von Holst - Hahn-Schickard, 79110 Freiburg, Germany

Matthias Kroschel - The Electrochemical Energy, Catalysis, and Materials Science Group, Department of Chemistry, Technical University Berlin, 10623 Berlin, Germany

Jessica Hübner - The Electrochemical Energy, Catalysis, and Materials Science Group, Department of Chemistry, Technical University Berlin, 10623 Berlin, Germany

Matthias Breitwieser - Electrochemical Energy Systems, IMTEK - Department of Microsystems Engineering, University of Freiburg, 79110 Freiburg, Germany; Hahn-Schickard, 79110 Freiburg, Germany

Complete contact information is available at: https://pubs.acs.org/10.1021/acsaem.0c00735

\section{Notes}

The authors declare no competing financial interest.

\section{ACKNOWLEDGMENTS}

The authors gratefully acknowledge financial support of this work by the Federal Ministry of Education and Research in Germany within the project NeutroSense (grant: 05KI9VFA) and the Ministry of Economy of Baden-Wuerttemberg within the project DirectMEA. 


\section{REFERENCES}

(1) Schmidt, O.; Gambhir, A.; Staffell, I.; Hawkes, A.; Nelson, J.; Few, S. Future cost and performance of water electrolysis: An expert elicitation study. Int. J. Hydrogen Energy 2017, 42, 30470-30492.

(2) Babic, U.; Suermann, M.; Büchi, F. N.; Gubler, L.; Schmidt, T. J. Critical Review-Identifying Critical Gaps for Polymer Electrolyte Water Electrolysis Development. J. Electrochem. Soc. 2017, 164, F387-F399.

(3) Carmo, M.; Fritz, D. L.; Mergel, J.; Stolten, D. A comprehensive review on PEM water electrolysis. Int. J. Hydrogen Energy 2013, 38, 4901-4934.

(4) Bertuccioli, L.; Chan, A.; Hart, F.; Lehner, F.; Madden, B.; Staden, E. Development of Water Electrolysis in the EU by E4tech Sarl with Element Energy Ltd for Fuel Cells and Hydrogen Joint Undertaking, 2014; pp 35-36.

(5) Ayers, K.; Danilovic, N.; Ouimet, R.; Carmo, M.; Pivovar, B.; Bornstein, M. Perspectives on Low-Temperature Electrolysis and Potential for Renewable Hydrogen at Scale. Annu. Rev. Chem. Biomol. Eng. 2019, 10, 219-239.

(6) Neyerlin, K. C.; Gu, W.; Jorne, J.; Clark, A., Jr.; Gasteiger, H. A. Study of the Exchange Current Density for the Hydrogen Oxidation and Evolution Reactions. J. Electrochem. Soc. 2007, 154, B631.

(7) Moseley, P. T.; Garche, J. Electrochemical Energy Storage for Renewable Sources and Grid Balancing; Elsevier Science: 2014.

(8) Feng, Q.; Yuan, X.; Liu, G.; Wei, B.; Zhang, Z.; Li, H.; Wang, H. A review of proton exchange membrane water electrolysis on degradation mechanisms and mitigation strategies. J. Power Sources 2017, 366, 33-55.

(9) Spöri, C.; Kwan, J. T. H.; Bonakdarpour, A.; Wilkinson, D. P.; Strasser, P. The Stability Challenges of Oxygen Evolving Catalysts: Towards a Common Fundamental Understanding and Mitigation of Catalyst Degradation. Angew. Chem., Int. Ed. 2017, 56, 5994-6021.

(10) Price, E. Durability and Degradation Issues in PEM Electrolysis Cells and its Components. Johnson Matthey Technol. Rev. 2017, 61, $47-51$.

(11) Fouda-Onana, F.; Chandesris, M.; Médeau, V.; Chelghoum, S.; Thoby, D.; Guillet, N. Investigation on the degradation of MEAs for PEM water electrolysers part I: Effects of testing conditions on MEA performances and membrane properties. Int. J. Hydrogen Energy 2016, 41, 16627-16636.

(12) Bernt, M.; Siebel, A.; Gasteiger, H. A. Analysis of Voltage Losses in PEM Water Electrolyzers with Low Platinum Group Metal Loadings. J. Electrochem. Soc. 2018, 165, F305-F314.

(13) Schuler, T.; Schmidt, T. J.; Büchi, F. N. Polymer Electrolyte Water Electrolysis: Correlating Performance and Porous Transport Layer Structure: Part II. Electrochemical Performance Analysis. J. Electrochem. Soc. 2019, 166, F555-F565.

(14) Lettenmeier, P.; Kolb, S.; Sata, N.; Fallisch, A.; Zielke, L.; Thiele, S.; Gago, A. S.; Friedrich, K. A. Comprehensive investigation of novel pore-graded gas diffusion layers for high-performance and cost-effective proton exchange membrane electrolyzers. Energy Environ. Sci. 2017, 10, 2521.

(15) Rozain, C.; Mayousse, E.; Guillet, N.; Millet, P. Influence of iridium oxide loadings on the performance of PEM water electrolysis cells: Part II - Advanced oxygen electrodes. Appl. Catal., B 2016, 182, 123-131.

(16) Nong, H. N.; Gan, L.; Willinger, E.; Teschner, D.; Strasser, P. IrOx core-shell nanocatalysts for cost- and energy-efficient electrochemical water splitting. Chem. Sci. 2014, 5, 2955-2963.

(17) Gawande, M. B.; Goswami, A.; Asefa, T.; Guo, H.; Biradar, A. V.; Peng, D.-L.; Zboril, R.; Varma, R. S. Core-shell nanoparticles: Synthesis and applications in catalysis and electrocatalysis. Chem. Soc. Rev. 2015, 44, 7540-7590.

(18) Park, J. E.; Kim, S.; Kim, O.-H.; Ahn, C.-Y.; Kim, M.-J.; Kang, S. Y.; Jeon, T. I.; Shim, J.-G.; Lee, D. W.; Lee, J. H.; Cho, Y.-H.; Sung, Y.-E. Ultra-low loading of $\mathrm{IrO} 2$ with an inverse-opal structure in a polymer-exchange membrane water electrolysis. Nano Energy 2019, $58,158-166$
(19) Lewinski, K. A.; van der Vliet, D.; Luopa, S. M. NSTF Advances for PEM Electrolysis - the Effect of Alloying on Activity of NSTF Electrolyzer Catalysts and Performance of NSTF Based PEM Electrolyzers. ECS Trans. 2015, 69, 893-917.

(20) Yu, A.; Lee, C.; Kim, M. H.; Lee, Y. Nanotubular IridiumCobalt Mixed Oxide Crystalline Architectures Inherited from Cobalt Oxide for Highly Efficient Oxygen Evolution Reaction Catalysis. ACS Appl. Mater. Interfaces 2017, 9, 35057-35066.

(21) Alia, S. M.; Shulda, S.; Ngo, C.; Pylypenko, S.; Pivovar, B. S. Iridium-Based Nanowires as Highly Active, Oxygen Evolution Reaction Electrocatalysts. ACS Catal. 2018, 8, 2111-2120.

(22) Ghadge, S. D.; Velikokhatnyi, O. I.; Datta, M. K.; Shanthi, P. M.; Tan, S.; Damodaran, K.; Kumta, P. N. Experimental and Theoretical Validation of High Efficiency and Robust Electrocatalytic Response of One-Dimensional (1D) (Mn,Ir)O 2:10F Nanorods for the Oxygen Evolution Reaction in PEM-Based Water Electrolysis. ACS Catal. 2019, 9, 2134-2157.

(23) Bühler, M.; Holzapfel, P.; McLaughlin, D.; Thiele, S. From Catalyst Coated Membranes to Porous Transport Electrode Based Configurations in PEM Water Electrolyzers. J. Electrochem. Soc. 2019, 166, F1070.

(24) Brunauer, S.; Emmett, P. H.; Teller, E. Adsorption of Gases in Multimolecular Layers. J. Am. Chem. Soc. 1938, 60, 309-319.

(25) Ahadi, M.; Tam, M.; Stumper, J.; Bahrami, M. Electronic conductivity of catalyst layers of polymer electrolyte membrane fuel cells: Through-plane vs. in-plane. Int. J. Hydrogen Energy 2019, 44, 3603-3614.

(26) Cherevko, S.; Reier, T.; Zeradjanin, A. R.; Pawolek, Z.; Strasser, P.; Mayrhofer, K. J.J. Stability of nanostructured iridium oxide electrocatalysts during oxygen evolution reaction in acidic environment. Electrochem. Commun. 2014, 48, 81-85.

(27) Cherevko, S.; Geiger, S.; Kasian, O.; Mingers, A.; Mayrhofer, K. J.J. Oxygen evolution activity and stability of iridium in acidic media. Part 2. - Electrochemically grown hydrous iridium oxide. J. Electroanal. Chem. 2016, 774, 102-110.

(28) Pfeifer, V.; Jones, T. E.; Velasco Vélez, J. J.; Massué, C.; Arrigo, R.; Teschner, D.; Girgsdies, F.; Scherzer, M.; Greiner, M. T.; Allan, J.; Hashagen, M.; Weinberg, G.; Piccinin, S.; Hävecker, M.; KnopGericke, A.; Schlögl, R. The electronic structure of iridium and its oxides. Surf. Interface Anal. 2016, 48, 261-273.

(29) Reier, T.; Teschner, D.; Lunkenbein, T.; Bergmann, A.; Selve, S.; Kraehnert, R.; Schlogl, R.; Strasser, P. Electrocatalytic Oxygen Evolution on Iridium Oxide: Uncovering Catalyst-Substrate Interactions and Active Iridium Oxide Species. J. Electrochem. Soc. 2014 161, F876-F882.

(30) Nong, H. N.; Gan, L.; Willinger, E.; Teschner, D.; Strasser, P. IrOx core-shell nanocatalysts for cost- and energy-efficient electrochemical water splitting. Chem. Sci. 2014, 5, 2955-2963.

(31) Nong, H. N.; Oh, H.-S.; Reier, T.; Willinger, E.; Willinger, M.G.; Petkov, V.; Teschner, D.; Strasser, P. Oxide-supported $\operatorname{IrNiO}(\mathrm{x})$ core-shell particles as efficient, cost-effective, and stable catalysts for electrochemical water splitting. Angew. Chem., Int. Ed. 2015, 54, 2975-2979.

(32) Nong, H. N.; Reier, T.; Oh, H.-S.; Gliech, M.; Paciok, P.; Vu, T. H. T.; Teschner, D.; Heggen, M.; Petkov, V.; Schlögl, R.; Jones, T.; Strasser, P. A unique oxygen ligand environment facilitates water oxidation in hole-doped $\mathrm{IrNiOx}$ core-shell electrocatalysts. Nat. Catal 2018, 1, 841-851.

(33) Reier, T.; Pawolek, Z.; Cherevko, S.; Bruns, M.; Jones, T.; Teschner, D.; Selve, S.; Bergmann, A.; Nong, H. N.; Schlögl, R.; Mayrhofer; Karl, J. J.; Strasser, P. Molecular Insight in Structure and Activity of Highly Efficient, Low-Ir Ir-Ni Oxide Catalysts for Electrochemical Water Splitting (OER). J. Am. Chem. Soc. 2015, 137, 13031-13040.

(34) Oh, H.-S.; Nong, H. N.; Reier, T.; Bergmann, A.; Gliech, M.; Ferreira de Araújo, J.; Willinger, E.; Schlögl, R.; Teschner, D.; Strasser, P. Electrochemical Catalyst-Support Effects and Their Stabilizing Role for IrOx Nanoparticle Catalysts during the Oxygen Evolution Reaction. J. Am. Chem. Soc. 2016, 138, 12552-12563. 
(35) Oh, H.-S.; Nong, H. N.; Strasser, P. Preparation of Mesoporous Sb-, F-, and In-Doped SnO 2 Bulk Powder with High Surface Area for Use as Catalyst Supports in Electrolytic Cells. Adv. Funct. Mater. 2015, 25, 1074-1081.

(36) Kroschel, M.; Bonakdarpour, A.; Kwan, J. T. H.; Strasser, P.; Wilkinson, D. P. Analysis of oxygen evolving catalyst coated membranes with different current collectors using a new modified rotating disk electrode technique. Electrochim. Acta 2019, 317, 722736.

(37) van Pham, C.; Bühler, M.; Knöppel, J.; Bierling, M.; Seeberger, D.; Escalera-López, D.; Mayrhofer, K. J.J.; Cherevko, S.; Thiele, S. $\mathrm{IrO}_{2}$ coated $\mathrm{TiO}_{2}$ core-shell microparticles advance performance of low loading proton exchange membrane water electrolyzers. Appl. Catal., B 2020, 269, 118762.

(38) Mo, J.; Kang, Z.; Retterer, S. T.; Cullen, D. A.; Toops, T. J.; Green, J. B.; Mench, M. M.; Zhang, F.-Y. Discovery of true electrochemical reactions for ultrahigh catalyst mass activity in water splitting. Science Advances 2016, 2, e1600690.

(39) Alia, S. M.; Rasimick, B.; Ngo, C.; Neyerlin, K. C.; Kocha, S. S.; Pylypenko, S.; Xu, H.; Pivovar, B. S. Activity and Durability of Iridium Nanoparticles in the Oxygen Evolution Reaction. J. Electrochem. Soc. 2016, 163, F3105-F3112.

(40) Suermann, M.; Takanohashi, K.; Lamibrac, A.; Schmidt, T. J.; Büchi, F. N. Influence of Operating Conditions and Material Properties on the Mass Transport Losses of Polymer Electrolyte Water Electrolysis. J. Electrochem. Soc. 2017, 164, F973-F980.

(41) Bernt, M.; Gasteiger, H. A. Influence of Ionomer Content in IrO 2 / TiO 2 Electrodes on PEM Water Electrolyzer Performance. J. Electrochem. Soc. 2016, 163, F3179-F3189.

(42) Bernt, M.; Siebel, A.; Gasteiger, H. A. Analysis of Voltage Losses in PEM Water Electrolyzers with Low Platinum Group Metal Loadings. J. Electrochem. Soc. 2018, 165, F305-F314.

(43) Su, H.-N.; Liao, S.-J.; Shu, T.; Gao, H.-L. Performance of an ultra-low platinum loading membrane electrode assembly prepared by a novel catalyst-sprayed membrane technique. J. Power Sources 2010, $195,756-761$.

(44) Bender, G.; Carmo, M.; Smolinka, T.; Gago, A.; Danilovic, N.; Mueller, M.; Ganci, F.; Fallisch, A.; Lettenmeier, P.; Friedrich, K. A.; Ayers, K.; Pivovar, B.; Mergel, J.; Stolten, D. Initial approaches in benchmarking and round robin testing for proton exchange membrane water electrolyzers. Int. J. Hydrogen Energy 2019, 44, 9174-9187. 